\title{
Business Internal Auditing - An Effective Approach in Developing Sustainable Management Systems
}

\author{
Jona PUCI ${ }^{1}, \mathrm{PhD}$ (c), Suzana GUXHOLLI ${ }^{1}$, Prof.Dr.
}

\begin{abstract}
Sustainability is a concept that expands on a larger perspective than the economic, environmental, and social challenges faced by a business on the daily and future operations. Sustainability refers to the ethical dimension of these operations, affecting the stakeholders of the organization and the planet on a larger scale. In this sense, more and more, the Board of Directors and other stakeholders of companies consider sustainable development as an essential part of corporate governance. In nowadays business culture, the success of a company is not only measured in terms of monetary profitability, but also in the sense of social awareness and consciousness. An increasing number of businesses are proactively adapting their internal management systems to adjust for the new requirements and transform it in a competitive advantage. These developments provide opportunities for internal auditing to contribute with its independent role within the company and objective assurance services of the internal processes, in generating sustainable value and performance of the organization. In this perspective, the aim of this study is to examine the system of sustainable internal audit that is an indispensable element for the development and well performance of sustainable management systems.
\end{abstract}

Keywords: Internal Auditing, Corporate Social Responsibility, Business, Corporate Governance; Sustainable Development, Sustainable Management Systems

\section{Introduction}

Businesses have an important role in the life of people and countries; therefore, successful businesses are critical for the development of the economy (Rajan and Zingale, 1998). Researchers view them as stimulus in economic, social, and political progress. Hence, it is necessary to understand the process and the variables that encourage or restrict business growth. Burke and Litwin (2001) refer to a business as a system made up subsystems to achieve efficiency. The impact of any element in a business such as management, reporting, auditing, culture, structure etc. should not be considered independently. Ignoring any of these components may bring losses to the organization that is materialized in decrease of sales, loss of market share, increase in costs, etc. Recognizing all these areas, businesses need to develop effective auditing policies to ensure sustainability.

Sustainability, in itself, is a concept that expands on a larger perspective than the economic, environmental, and social challenges faced by an organization on the daily and future operations. Sustainability refers to the ethical dimension of these operations, affecting the stakeholders of the organization and the planet on a larger scale. In this sense, more and more, the Board of Directors and other stakeholders of companies 
consider sustainable development as an essential part of corporate governance. In nowadays business, the success of a company is not only measured in terms of monetary profitability, but also in the sense of social awareness and consciousness. In addition, investors, employees and customers are increasingly becoming more demanding toward businesses in terms of socially responsible commitments. In this perspective, progressively, companies are presenting separate reports on sustainability as part of their annual reports to assure stakeholders and society regarding the sustainability of its operations (Ballou, Heitger, Landes, \& Adams, 2006).

An increasing number of organizations are proactively adapting their internal management systems to adjust for the new requirements and transform it in a competitive advantage. These developments provide opportunities for internal auditing to contribute with its independent role within the company and objective assurance services of the internal processes, in generating sustainable value and performance of the organization, as auditors as well as consultants. The main objective of the internal auditing role consists on improving any process within the organization with the aim of enhancing revenue and reducing risk. Additionally, as part of the core task of an internal auditor is considered the provision to the management of well-restructured and updated information regarding the operational and compliance issues and intermittent the participation in the stakeholder dialogue process (Kolk, 2008).

Furthermore, the increasing importance of these dimensions and the respective impact on risk management results in further challenges concerning the control environment and, the establishment of effective sustainability management systems, which will assure clarity, transparency and trust. The contribution of the internal auditor in this process is twofold. During the first phase, it assists the management in establishing a sustainability management system and after implementation, performs system audits. According to Nieuwlands (2007), the contribution of internal auditors would extend in reviewing the strategy designed and implemented by the company; controlling the adequacy of the employed systems in line with the objectives and targets of the strategy. Additionally, they should be engaged in assessing the effectiveness of the reporting line; implementation and operation within the sustainability management system; and test the reliability of quantified reports through the evaluation of performance indicators. Nevertheless, the internal auditor has to acquire knowledge regarding sustainability practices and the relevant applicable audit techniques. Nowadays, internal audit function is considered among the most significant factors in generating sustainable value, which advances the value and performance of the organization. Consequently, organizations have to consign adequate importance and acting power to internal auditing in creating a sustainable audit system. In this perspective, the aim of this study is to examine the system of sustainable internal audit that is the indispensable element for the development and well performance of sustainability management systems.

\section{Sustainability Defined}

\subsection{Sustainable Development Goals}

In the nowadays business environment and wider, sustainable development is considered as the guiding principle for long-term global development. Referring to the definition provided by World Commission on Environment and Development, 1987; 
sustainable development refers to "development that meets the needs of the present without compromising the ability of future generations to meet their own needs". Moreover, sustainable development aims at achieving development in three pillars: economic, social and environmental protection, in a balanced manner. An important development was the Rio Earth Summit in 1992, where the international community gathered in Rio de Janeiro, Brazil, to discuss means to operationalize sustainable development. During this event, the participant approved the so-known Agenda 21, detailed with specific action plans to realize sustainable development at national, regional and international levels. In 2002, the World Summit on Sustainable Development adopted the Johannesburg Plan of Implementation, which built upon the progress and lessons learned since the Earth Summit, and what is more important provided for a more focused approach presenting defined quantifiable steps to be undertaken and timebound targets and goals. In 2012, world leaders gathered once again in Rio de Janeiro to secure renewed political commitment to sustainable development and address new and emerging challenges.

In order to operationalize sustainability in terms of its effective implementation in companies and other organization operations, in 2000 the leaders of 189 countries gathered at the United Nations headquarters and signed the historic Millennium Declaration. In this declaration, they committed to achieve 8 measurable Millennium Development Goals (MDG), by the target date of 2015. Despite these goals were reasonably measurable and implementable, results were uneven, especial in terms of ending extreme poverty. As a result, UN General Assembly agreed upon a set of 17 Sustainable Development Goals (SDG) in July 2014. The new SDGs and the global development agenda will be implemented in the period 2015-2030.

Table 1: Global Development Agenda

Goal 1. End poverty in all its forms everywhere

Goal 2. End hunger, achieve food security and improved nutrition and promote sustainable agriculture

Goal 3. Ensure healthy lives and promote well-being for all at all ages

Goal 4. Ensure inclusive and equitable quality education and promote lifelong learning opportunities for all

Goal 5. Achieve gender equality and empower all women and girls

Goal 6. Ensure availability and sustainable management of water and sanitation for all

Goal 7. Ensure access to affordable, reliable, sustainable and modern energy for all

Goal 8. Promote sustained, inclusive and sustainable economic growth, productive employment and decent work for all

Goal 9. Build resilient infrastructure, promote inclusive and sustainable industrialization and foster innovation

Goal 10. Reduce inequality within and among countries

Goal 11. Make cities and human settlements inclusive, safe, resilient and sustainable

Goal 12. Ensure sustainable consumption and production patterns

Goal 13. Take urgent action to combat climate change and its impacts

Goal 14. Conserve and sustainably use the oceans, seas and marine resources for sustainable development

Goal 15. Protect, restore and promote sustainable use of terrestrial ecosystems, sustainably 
manage forests, combat desertification, and halt and reverse land degradation and halt biodiversity loss

Goal 16. Promote peaceful and inclusive societies for sustainable development, provide access to justice for all and build effective, accountable and inclusive institutions at all levels

Goal 17. Strengthen the means of implementation and revitalize the Global Partnership for Sustainable Development

Source: United Nations, Open Working Group; Global Goals, wmw. globalgoals.org

Hence, based on these developments for the implementation of sustainability in various pillars of development, more and more companies are adapting their systems based on these directives (please refer to paragraph 2.3).

\subsection{Corporate sustainable development}

Traditionally, the concept of sustainability was considered by most companies mostly related to the environmental issue of reducing energy and waste disposal costs or to the social issues of supporting community causes. Hence, it was not directly related to the economic profitability of the company's core business. Anyhow, increasingly companies have to confront and adapt to a range of disruptive forces, such as urbanization, globalization, intense competition for resources, revolution in technology, innovative business models. On the other side, there is an increasing pressure from regulators and other stakeholders forcing companies to become more accountable and transparent. As a result, sustainability is moving from the companies' sideline operation to the mainstream ones. Therefore, corporations have to implement the above principles in a multi-facet manner to the products, practices, procedures and applied policies in order to implement measurable sustainable development (Bowman \& Ambrosini, 2000). The three pillars supporting sustainable development may be extended to the corporate level and hence, it is assumed that this type of development is attained with the necessary conditions and intersection of the three principles. Under the new landscape, companies continuously face with future uncertain energy costs, impending regulation on carbon emissions, raw materials and natural resources access; hence making environmental sustainability a key consideration in their strategy.

The approved SDGs are not legally binding and their implementation is the main responsibility of governments. Nevertheless, in practice they serve as de facto regulation at macro level with the designation of national regulation and incentives; and at micro level as companies re adapting their operational systems to implement these goals. As corporations enhance their operations under this perspective and align with the SDGs, they will be able to better evaluate their role in supporting or hindering a government to achieve its goals. Additionally, they will be able to grasp the opportunity of evidencing and maintaining their sustainability in operations. Furthermore, these companies will also have a competitive advantage over those that are not able to provide their contribution or revise their strategies accordingly. Another important perspective of implementing sustainability in operations is risk management, in terms of evaluating existing and potential risks and accordingly adjusting to minimize them. Referring to the World Economic Forum's Global Risks Report 2016, the top five long-term risks are classified as sustainability risks. 
Table 2: Top Global Risks

\begin{tabular}{|l|l|l|}
\hline Risk & Likelihood & SDG relevance \\
\hline Water crises & $39.80 \%$ & SDG 6 Clean water and sanitation \\
\hline $\begin{array}{l}\text { Failure of climate change mitigation } \\
\text { and adaptation }\end{array}$ & $36.70 \%$ & SDG 13 Climate action \\
\hline $\begin{array}{l}\text { Extreme weather events } \\
\text { Food crises }\end{array}$ & $26.50 \%$ & SDG 9 Industry, innovation and infrastructure \\
\hline Profound social instability & $25.20 \%$ & SDG 2 Zero hunger \\
\hline
\end{tabular}

Source: https://www.weforum.org/agenda/2016/01/what-are-the-top-global-risks-for-2016

\subsection{Evidence at a glance}

Referring to a research performed by PwC entitles "Make it your business: Engaging with the Sustainable Development Goals" (2015), the following were amongst the most prominent results:

- Awareness: SDG awareness amongst the business community is very high at the level of $92 \%$ compared to the $33 \%$ citizens aware of SDGs)

- Responsibility: 49\% of business responders and 44\% of citizens ranked government first in having a prime responsibility to achieve the SDGs

- Action: Despite only 10\% business responders ranked business with prime responsibility, $71 \%$ of business state they are already planning how they will respond to the SDGs. Nevertheless, only $13 \%$ of businesses have identified the tools they need and only $29 \%$ of businesses are setting goals, regarding measurements, indicators and objectives to be achieved.

- Engagement. We should be optimistic that engagement will increase by 2020: 22\% of business responders say they are doing nothing right now, but this drops to $4 \%$ when thinking about what they'll do in 5 years.

- Citizen significance: $90 \%$ of citizens believe it is important that business signs up to the SDGs and $78 \%$ more likely to buy the goods and services of companies that had signed up to the SDGs.

Considering the importance that the businesses are dedicating to the process of integrating sustainable operations and systems in their companies, businesses and consultants have also developed tools and methods to identify those SDGs, which are most relevant given the countries and sectors of operation. Significant contribution have been made in order to evaluate which goals companies can best contribute to and identify the significant risks and prospective opportunities in terms of core products, activities and across the supply chain.

\section{Internal Audit Contribution}

\subsection{Internal Audit Role}

The aim of the internal auditing function is to enhance processes within the organization with the objective of increasing revenue and reducing risk. Internal auditing assignments and tasks are internally developed and they are prioritized considering the level of risk connected with identified processes and areas. The senior management of companies, considering also the recommendations from departments including accounting, finance, operations, sales, marketing, etc., prioritizes these areas. The audit 
process and risk factors are regularly cyclic procedural within the same department due to the nature of operations of businesses. In this sense, internal auditors must create a database of knowledge and best practices of past audit procedures to refer upon in future audit opportunities or validation requests. The role of the internal auditors in sustainability is required by the standards but also by the requirements of the companies to enhance operations in order to enhance profitability and reduce risks. In their study, Ridley et al. (2011) have argued that in spite of the growing acknowledgment that companies have on reporting the pertinent sustainability matters, stakeholders do not well appreciate that these reports are independently assured by external auditors. Hence, in their paper they argue that this type of assurance may be provided by the internal audit function that can make a noteworthy contribution to effective corporate governance. Furthermore, the IIA (Institute of Internal Auditors) standards on governance outline four methods an internal auditor should influence corporate authority. While evaluating the processes of a specific department, the internal are should aim to enhance that process as it relates to corporate governance and sustainability. According to the standards, these four methods are briefly discussed as follows. ${ }^{1}$

${ }^{1}$ https://na.theiia.org/standards-guidance/mandatory-guidance/Pages/Standards.aspx 


\section{- Establish and Convey}

Corporate responsibility and sustainability reporting currently is not yet standardized at the global level and the reporting has expanded beyond the classical one for environmental and industrial issues. Despite the variation in format and content which reporting has undergone through the years, any company which aims to disclose and publish this information, as a first step has to assess and define the values and goals be argued and reflected in the report. For instance, values must be accurately defined and justified with information on how the company is supporting those values in everyday operations. Additionally, goals must be defined and supplemented by financial, operational, or philanthropic goals. In this perspective, internal auditors bear the responsibility of understanding and relating the specified values and goals to the audit jobs and projects which are executed that is executed. More importantly, the internal auditor might evaluate a case where the specified values and goals presented a risk in an area or procedure. Hence, the auditor is obliged to present this risk to the management of the company.

\section{- Monitor}

As a first step in the process, the performance goals and targets are determined and disseminated internally within the company and to other public stakeholders. Furthermore, an execution plan has to be prepared where there should be outlined the methods for accomplishing the specified objectives. In terms of internal auditing of the process of corporate governance, the roles consist on observing and examining the implementation of the execution plan and also control the related outcomes (Stewart \& Subramaniam, 2010). This point is of special importance since a certain goal may be considered accomplished by the leadership, there may be raised other issues by the internal auditors in terms of identifying new or existing risks.

\section{- Validate}

In today's business world, the reputation of the firm is highly perceived as dependent on the ethical and moral actions of executive management. Therefore, the corporate leadership and senior management are responsible and accountable for all actions within the corporation. In this perspective, the internal auditors have to assess targeted goals in order to guarantee that the distributed reported results by the organization's management are accurate as claimed and communicated both internally and externally, in all published reports of the corporation such as the annual report or separate corporate responsibility report.

\section{- Uphold Standards}

In nowadays business environment, all external stakeholders expect that the standards of companies will be maintained while attempting to identify every opportunity or situations, which may present a violation of standard. In order to circumvent these situations from being exposed externally, internal auditors must first ascertain and communicate the related findings to the management. Furthermore, by completing the three preceding actions of establishing and conveying, monitoring and validating, the internal auditor may meaningfully contribute to upholding the standards of the corporation (Kates, Parris \& Leiserowitz, 2005). What is more important, the risk reduction resulting from effective internal audit findings will support the management in more effectively preserving and maintaining corporate values. In more details, what is 
perceived nowadays as the role of the internal auditor in ensuring sustainability, consists on several tasks and procedures related to the normal work flow of the auditors. For instance, the internal auditors may identify and determine where the pressures are likely to be and hence raise awareness for sustainability strategy and action plan. Moreover, the internal auditors may support in prioritizing the raised issues and risk not only on sustainability terms but on commercial terms as well. Furthermore, their role may be extended in mapping the corporation's ambitions for sustainability, align and integrate the sustainability strategy into the overall corporate strategy, and develop and implement a sustainability programme detailed with priorities, main actors, milestones, performance indicators and measurable targets.

\section{Sustainability Strategy}

In today's business environment, building ad implementing a comprehensive sustainability strategy provides numerous benefits for companies, especially in contributing for the long-term growth and profitability. For instance, the implementation of such a strategy enhances a company's reputation, motivates and strengthens employee engagement and attracts and retains top talents. Very importantly for nowadays success, it drives innovation that leads to market differentiation. Additionally, providing a clear documented vision for sustainability demonstrates compliance and satisfies consumers and other stakeholders. Considering the importance and positive implications of a sustainability strategy, developing and implementing an accurate sustainability vision and transforming it into a long term strategic plan is a challenging process, especially when aiming to create long lasting value to the company and related stakeholders. In this perspective, a sustainability strategy should first identify issues and goals and the consequential short and long term ambitions. In addition, in this strategy the company should assess the risks, support the arrangement and integration of a sustainability vision and develop and deliver a robust sustainability programme. All over again, the role of internal auditors can be of crucial importance in the development of sustainability strategy and the implementation programme.

\subsection{Governance, risk and compliance}

Progressively, national and international companies are striving to comply with the set standards and regulations in terms of increasing restrictions on the materials they use in the production process. As businesses face this regulatory environment in terms of governance, risk and compliance; there is a growing necessity to establish governance practices with a focus on sustainability and compliance. Considering the knowledge of the internal auditor of the procedures and processes of the company and drawing from the recent developments globally, the internal auditor have the know-how and expertise to advise the company on various topics related to the above issues.

For instance, the internal auditor can assist by performing the following tasks:

- Assess the compliance levels of the company by examining all sustainable development legal requirements, company policies, and industry or voluntary codes 
- In case of absence, create codes of conduct, policies and procedures which will are up to the stakeholders' expectations and guarantee that the company's values are respected and strengthened.

- Design and implement effective frameworks and approaches which aim at engaging employees in the sustainability strategy.

- Outline risks and opportunities in order for employees and other stakeholders to comprehend and support the sustainability strategy

- Develop clear and coherent communications channels to ensure optimal employee engagement.

- Manage risk and regulatory compliance in order to asses their impact on the company's strategy and operations.

\subsection{Assurance and reporting}

Apart from ensuring sustainability in the company's process, the management has to make sure that the stakeholders are also dully informed regarding the organization's sustainability performance. In this aspect, the company should accurately report on its corporate activities regarding sustainability issues such as climate change, resource scarcity and socially responsible investing (Conner, 1991). To facilitate reporting, senior management has to define clear sustainability metrics and ensure that timely and transparent reporting truthfully reflects advancement made in this perspective. In terms of assurance and reporting, the internal auditor may also play an important role by performing the following activities.

- Perform internal audits to comprehend the effectiveness of the internal controls

- $\quad$ Review current reporting face to face with best practices proposed by external experts and industry

- Integrate the life cycle of the products and services with the company's sustainability goals.

- Suggest operational improvements, beyond the compliance requirements in order to provide for forward-looking strategy

- Align measurable sustainability objectives with corporate strategy, considering financial, operational and regulatory performance measures.

stakeholders

- Verify company's data against social and environmental benchmarks in line with market standards.

\subsection{Supply chain and operations}

More and more companies are considering the impact that their operations have on the environment and the overall impact on the communities they operate. The importance of comprehending these impacts refers to the resulting improvements to the supply chain, daily operations, financial performance and corporate strategy. Hence, to ensure that the supply chain will achieve the required financial and sustainability metrics, the internal auditor may assist in the following tasks. 
- $\quad$ Evaluate the risks related to the supply chain

- Monitor environmental, social and governance risks related to the supply chain.

- $\quad$ Assess and implement best practices from the industry

- Asses the characteristics of suppliers and adjust accordingly if not sustainable.

- Restructure the company'sl supply chains to ensure cost-efficiency and minimal effect on the society, environment and natural resources.

\subsection{Policy \& Economics}

In order to effectively address the issue of climate change, the world economies are progressively referring to a more dynamic and innovative approach in performing their operations. The "green agenda" is designed by international policy makers and aims at reducing climate change and ensuring sustainable environmental development. This agenda is more and more integrated in the business operations in terms of globalwide introduced concepts of green growth, green jobs and green stimulus packages. In this perspective, new opportunities can arise for the public and private sectors. Internal auditors, as employees with accurate knowledge of operations and procedures of the company, can assist in the process in the following ways, by also integrating the directives of governments, policy makers and international organisations.

- Preform environmental and social cost-benefit analysis for the company's current operations and practices.

- Ensure that compliance obligations are fulfilled through proper reporting for environmental and social engagement, transfer pricing and carbon-related data.

- Introduce in the company the concept of "climate smart" operations and support in designing and implementing sustainable business models which are resilient to economic change, climate change, or regulatory change. Hence, the company may fully benefit from the cost saving opportunities

- Interpret and implement ongoing policy announcements to evaluate the impact on the company's business opportunities

- Manage sustainable development goals by continuously performing valuations and due diligence analysis of sustainability practices within the company.

\subsection{Tax \& the regulatory environment}

Environmental regulations and taxes are continuously increasing in both the variety of taxes and their scope. It is of vital importance for the nowadays business environment to accurately comprehend the impact of the current and scheduled business operations in order to perform informed strategic decision-making and benefit from evolving cost reducing opportunities. In this perspective, the role of the internal auditor is supportive in the following issues:

- Improve the company's reputation directly through sustainability-focused initiatives

- $\quad$ Comprehend the tax department's role in supporting sustainability strategy

- $\quad$ Assess the present global exposure to environmental taxes and regulations

- Optimize the tax position from a sustainability perspective 
- $\quad$ Comprehend the sustainability compliance obligations

- Benefit from subsidies, grants, taxes and other incentives

- $\quad$ Prepare for future policy developments.

\section{Conclusions \& Recommendations'}

As a conclusion we may state that the role of the internal audit of an organization may support the entity define their sustainability strategy and path toward achieving set objectives; ascertain challenging areas which presents risk for the company and opportunities for development as well; and provide insightful recommendations to the management to effectively direct operations, enhance profitability of the company and increase stakeholders' satisfaction. Moreover, the internal audit has the skills and know-how to assess the accuracy, consistency and reporting quality of data related to sustainability measurements and presented in the entity's reports in terms.

Nevertheless, further studies may be developed to further elaborate the topic. Future studies may focus on empirically testing the implications of this paper by quantifying the effect of implementing internal audit approach toward sustainability in corporations. Considering also the limited span of studies dedicated to developing markets, this kind of study may be of a great interest for the Albanian market, which is still an underdeveloped market where the concepts of sustainability are very innovative and under-implemented.

\section{References}

Ballou, B., Heitger, D. L., Landes, C. E., \& Adams, M. (2006). The future of corporate sustainability reporting. Journal of Accountancy, 202(6), 65.

Burke, W., Litwin, G. (2001). Performance Variability and the Relationship with TQM. In: Annual Meeting of the Academy of Management. Academy of Management Proceedings. Atlanta.

Bowman, C., \& Ambrosini, V. (2000). Value creation versus value capture: towards a coherent definition of value in strategy. British journal of management, 11(1), 1-15.

Conner, K. R. (1991). A historical comparison of resource-based theory and five schools of thought within industrial organization economics: do we have a new theory of the firm?. Journal of management, 17(1), 121-154.

Griggs, D., Stafford-Smith, M., Gaffney, O., Rockström, J., Öhman, M. C., Shyamsundar, P., ... \& Noble, I. (2013). Policy: Sustainable development goals for people and planet. Nature, 495(7441), 305-307.

Kates, R. W., Parris, T. M., \& Leiserowitz, A. A. (2005). What is sustainable development? Goals, indicators, values, and practice. Environment(Washington DC), 47(3), 8-21.

Kolk, A. (2008). Sustainability, accountability and corporate governance: exploring multinationals' reporting practices. Business Strategy and the Environment, 17(1), 1-15.

Nieuwlands, H. (2007). Auditing sustainable development. Internal auditor, 64(2), 91-93.

PwC. (2016). Sustainability and Internal Audit: Innovating to add value.

PwC. (2015) Make it your business: Engaging with the Sustainable Development Goals. United Kingdom

Rajan, R., and Zingales, L. (1998). Financial Dependence and Growth. The American Economic Review, 88(3), 559-586

Ridley, J., D'Silva, K., \& Szombathelyi, M. (2011). Sustainability assurance and internal auditing in emerging markets. Corporate Governance: The international journal of business in society, 11(4), 475-488.

Stewart, J., \& Subramaniam, N. (2010). Internal audit independence and objectivity: emerging research opportunities. Managerial auditing journal, 25(4), 328-360. 
World Economic Forum (2016). The Global Risks Report 2016 11th Edition. Geneva, Switzerland. 